\title{
External Tufted Cells: A Major Excitatory Element That Coordinates Glomerular Activity
}

\author{
Abdallah Hayar, Sergei Karnup, Matthew Ennis, and Michael T. Shipley \\ Department of Anatomy and Neurobiology, Program in Neuroscience, University of Maryland, Baltimore, Maryland 21201
}

The glomeruli of the olfactory bulb are the first site of synaptic processing in the olfactory system. The glomeruli contain three types of neurons that are referred to collectively as juxtaglomerular (JG) cells: external tufted (ET), periglomerular (PG), and short axon (SA) cells. JG cells are thought to interact synaptically, but little is known about the circuitry linking these neurons or their functional roles in olfactory processing. Single and paired whole-cell recordings were performed to investigate these questions. ET cells spontaneously fired rhythmic spike bursts in the theta frequency range and received monosynaptic olfactory nerve (ON) input. In contrast, all SA and most PG cells lacked monosynaptic ON input. PG and SA cells exhibited spontaneous, intermittent bursts of EPSCs that were highly correlated with spike bursts of ET cells in the same but not in different glomeruli. Paired recording experiments demonstrated that ET cells provide monosynaptic excitatory input to $\mathrm{PG} / \mathrm{SA}$ cells; the $\mathrm{ET}$ to $\mathrm{PG} / \mathrm{SA}$ cell synapse is mediated by glutamate. ET cells thus are a major excitatory linkage between $\mathrm{ON}$ input and other JG cells. Spontaneous bursting is highly correlated among ET cells of the same glomerulus, and ET cell activity remains correlated when all fast synaptic activity is blocked. The findings suggest that multiple, synchronously active ET cells synaptically converge onto single PG/SA cells. Synchronous ET cell bursting may function to amplify transient sensory input and coordinate glomerular output.

Key words: external tufted; bursting; dual recordings; coefficient of correlation; monosynaptic; synchrony

\section{Introduction}

Olfactory nerve $(\mathrm{ON})$ axons arising from olfactory receptor neurons expressing the same odorant receptor converge onto the same one or few glomeruli in each main olfactory bulb, where they synaptically terminate on the apical dendrites of mitral/ tufted cells and local juxtaglomerular (JG) neurons (for review, see Xu et al., 2000). Individual glomeruli, therefore, represent the odor profile of the receptor expressed by the uniform cohort of olfactory receptor neurons that innervate it. Individual odorants elicit specific spatial patterns of glomerular activity, and different odorants activate different patterns of glomeruli (Jourdan et al., 1980; Cinelli et al., 1995; Johnson and Leon, 2000a,b; Belluscio and Katz, 2001). Accordingly, each glomerulus is a functional unit for processing sensory input.

Synaptic integration within glomeruli involves multineuronal circuitry. Classic Golgi and electron microscopic studies (Pinching and Powell, 1971a,b) described at least three populations of JG neurons: (1) external tufted (ET), (2) periglomerular (PG), and (3) short axon (SA) cells, but little is known about the physiological characteristics of JG cells or their synaptic partners. Recently ET cells were found to have a distinctive physiological

Received April 12, 2004; revised June 14, 2004; accepted June 14, 2004.

This work was supported by National Institutes of Health Grants DC00347, DC02588, DC03195, and DC05676.

Correspondence should be addressed to Dr. Michael T. Shipley, Department of Anatomy and Neurobiology,

University of Maryland School of Medicine, 685 West Baltimore Street, Baltimore, MD 21201. E-mail: mshipley@umaryland.edu.

A. Hayar's and M. Ennis's present address: Department of Anatomy and Neurobiology, University of Tennessee Health Science Center, Memphis, TN 38163.

DOI:10.1523/JNEUROSCI.1367-04.2004

Copyright $\odot 2004$ Society for Neuroscience $\quad$ 0270-6474/04/246676-10\$15.00/0 profile characterized by a spontaneous activity pattern consisting of rhythmically occurring bursts of action potentials (Hayar et al., 2004). Rhythmical bursting is an intrinsic property of ET cells, in that it is independent of synaptic inputs. Much less is known about the physiology of PG and SA cells. One goal of the present study, therefore, was to characterize the spontaneous activity of PG and SA cells and to compare them with ET cells.

EM studies have shown that ON terminals form excitatory synapses with mitral and tufted cells and with an unknown population of PG cells (for review, see Kosaka et al., 1998); it is not known whether SA cells receive ON synapses. EM studies also indicate that there are extensive, intraglomerular dendrodendritic synapses between PG and presumed mitral and tufted cells, but to date it has not been possible to distinguish mitral and tufted cell dendrites at the EM level. Thus, it is not known whether ET cells receive ON synaptic input or whether ET cells synapse with PG and SA cells. A second goal of these experiments therefore was to determine whether ET cells receive monosynaptic ON input and whether ET cells are presynaptic to other JG neurons.

Single and paired whole-cell patch-clamp and extracellular recordings in rat olfactory bulb slices showed the following. (1) The spontaneous activity of PG and SA cells is characterized by intermittent bursts of EPSCs. (2) ET cells receive monosynaptic ON input; SA and the majority of PG cells have disynaptic or polysynaptic responses to ON stimulation. (3) ET cells have correlated spike bursting and provide excitatory, monosynaptic input to PG and SA cells. On the basis of these findings, we conclude that ET cells provide a major excitatory linkage of ON input to PG and SA cells. The results suggest that correlated bursting of ET of 
the same glomerulus may amplify sensory input and coordinate glomerular output.

\section{Materials and Methods}

Sprague Dawley rats (21-29 d old) of either sex were anesthetized with chloral hydrate and decapitated in accordance with Institutional Animal Care and Use Committee and National Institutes of Health guidelines. The olfactory bulbs were removed and immersed in sucrose-artificial CSF (sucrose-aCSF) equilibrated with $95 \% \mathrm{O}_{2} / 5 \% \mathrm{CO}_{2}, \mathrm{pH} 7.38$. The sucrose-aCSF had the following composition (in mM): $26 \mathrm{NaHCO}_{3}, 1$ $\mathrm{NaH}_{2} \mathrm{PO} 4,2 \mathrm{KCl}, 5 \mathrm{MgSO}_{4}, 0.5 \mathrm{CaCl}_{2}, 10$ glucose, and 248 sucrose. Horizontal slices ( $400 \mu \mathrm{m}$ thick) were cut with a microslicer (Ted Pella, Redding, CA). After a period of recovery at $30^{\circ} \mathrm{C}$ for $15 \mathrm{~min}$, slices were then incubated at room temperature $\left(22^{\circ} \mathrm{C}\right)$ in aCSF equilibrated with $95 \% \mathrm{O}_{2} / 5 \% \mathrm{CO}_{2}$ (composition in mM: $124 \mathrm{NaCl}, 26 \mathrm{NaHCO}_{3}, 3 \mathrm{KCl}$, $1.25 \mathrm{NaH}_{2} \mathrm{PO}_{4}, 2 \mathrm{MgSO}_{4}, 2 \mathrm{CaCl}_{2}$, and 10 glucose) until used. For recording, a single slice was placed in a recording chamber and perfused continuously at the rate of $1.5 \mathrm{ml} / \mathrm{min}$ with normal aCSF equilibrated with $95 \% \mathrm{O}_{2} / 5 \% \mathrm{CO}_{2}$. All recordings were performed at $30^{\circ} \mathrm{C}$. Neurons were visualized using an upright microscope (Olympus BX50WI, Tokyo, Japan) equipped for epifluorescence and near-infrared differential interference contrast optics.

Patch pipettes were pulled from borosilicate glass capillaries with an inner filament (1.5 mm outer diameter; Clark, Kent, UK) on a pipette puller (P-97, Sutter Instrument Company, Novato, CA) and filled with a solution of the following composition (in $\mathrm{mM}$ ): $134 \mathrm{~K}$-gluconate, $4 \mathrm{NaCl}$, $4 \mathrm{MgCl}_{2}, 10 \mathrm{HEPES}, 0.2$ EGTA, $3 \mathrm{Mg}_{2} \mathrm{ATP}, 0.3 \mathrm{Na}_{2} \mathrm{GTP}, 0.02 \%$ Lucifer yellow, and $0.2 \%$ biocytin (Molecular Probes, Eugene, OR). Osmolarity was adjusted to $270 \mathrm{mOsm}$ and $\mathrm{pH}$ to 7.3 . Extracellular recordings were obtained using patch pipettes filled with aCSF. The pipette resistance was 5-8 M $\Omega$. Dual recordings were made using two Axopatch-200B amplifiers (Axon Instruments, Foster City, CA). The junction potential was 9-10 $\mathrm{mV}$, and all reported voltage measurements are uncorrected for these potentials. Only neurons with access resistance $\leq 30 \mathrm{M} \Omega$ were included in this study. No series resistance compensation was performed. The input resistance of recorded neurons was measured between -60 and $-70 \mathrm{mV}$. Electrical stimulation (Grass S8800 stimulator, Astro-Med, West Warwick, RI) was performed using two stainless steel wires $(50 \mu \mathrm{m}$ in diameter; A-M Systems, Everett, WA), insulated except at their tips, positioned in the ON layer. Isolated, constant-current stimulus pulses of $10-200 \mu \mathrm{A}$ and $200 \mu \mathrm{sec}$ duration were applied. To compare response latencies of different JG cells with ON stimulation, the stimulating electrode was always placed in the ON layer immediately adjacent to the glomerulus where recordings were made.

Drugs and solutions of different ionic content were applied to the slice by switching the perfusion with a three-way electronic valve system. QX-314, gabazine, 6-cyano-7-nitroquinoxaline-2,3-dione (CNQX), and ( \pm )-2-amino-5-phosphopentanoic acid (APV) were purchased from Research Biochemicals International (Natick, MA).

Biocytin-filled cells were developed as described previously (Karnup and Stelzer, 1999). Briefly, fixed slices were embedded in 10\% gelatin and sectioned at $80 \mu \mathrm{m}$ thickness using a vibratome. The sections were reacted with $1 \% \mathrm{H}_{2} \mathrm{O}_{2}, 0.5 \%$ Triton X-100, ABC complex, and Ni-DAB chromagen. After dehydration, the sections were mounted in distrene plasticizer xylene. Two-dimensional reconstructions of filled neurons were made with Neurolucida software (MicroBrightField, Colchester, VT).

Analog signals were low-pass filtered at $2 \mathrm{kHz}$ (Axopatch 200B) and digitized at $5-10 \mathrm{kHz}$ using a Digidata-1200A interface and pClamp8 software (Axon Instruments). The detection of events (extracellularly recorded spikes and intracellularly recorded EPSCs) was performed offline using Mini analysis program (Synaptosoft, Decatur, GA). The times of occurrence of events were stored in American Standard Code for Information Interchange (ASCII) files and imported into Origin 7.0 (Microcal Software, Northampton, MA) for further analysis using algorithms written in LabTalk. Event train cross-correlograms (bin $=1$ or 2 $\mathrm{msec}$ ) were obtained using data acquired during 5-10 min in each recording condition. To compare the degree of correlation in different pairs, or in the same pair in different conditions, cross-correlograms were normalized to the firing rate of both cells, the bin width, and the sampling period (Mann-Metzer and Yarom, 1999). Thus, the correlation coefficients $(C)$ indicate how frequently one cell fires synchronous spikes with another cell compared with chance $(C=1)$. Cross-correlograms were normalized by dividing the counts in each bin by a coefficient $(N)$, which is the number of events expected by chance during one bin as follows: $N=F 1 \times F 2 \times P \times B$, where $F 1$ and $F 2$ are the mean frequencies of events (in Hertz) in the first and second cell, respectively, $P$ is the sampling period (in seconds) used for analysis, and $B$ is the duration (in seconds) of one bin. For autocorrelograms, F1 equals F2. A coefficient of correlation $(C)$ of $>1+3 \times$ SD (i.e., confidence limit, $>99.97 \%$ ) indicates significant positive correlation, in which SD is the standard deviation of the cross-correlation of the spike trains at time lags between 1.5 and $2 \mathrm{sec}$ (shift predictor method) (Gerstein and Perkel, 1972). This method is based on the idea that most neuronal interactions occur on a short time scale and on the assumption that the time shift $(1.5-2 \mathrm{sec})$ is much larger than the delay that is usually involved in neuronal interactions (Aertsen et al., 1989).

Membrane potential cross-correlograms were constructed from $10 \mathrm{sec}$ simultaneous recording samples from each pair of cells. Membrane potential traces were offset by their mean, and the spikes were truncated $>10 \mathrm{mV}$ from the mean; the traces were then reduced by group averaging to one point per $5 \mathrm{msec}$. Cross-correlograms of the conditioned traces were constructed and normalized by the square root of the product of the autocorrelation values of the two traces at zero lag time. Because spikes were removed by truncation and filtering, the coefficient of correlation (theoretical maximum $=1$ ) measures the degree to which changes in membrane potential of each cell were correlated. The coefficient of correlation of the membrane potentials $\left(C_{\mathrm{m}}\right)$ values were considered significant if they were at least three times higher than the $\mathrm{SD}$ of the $C_{\mathrm{m}}$ values of the shuffled membrane potentials (confidence limit, >99.97\%). Data, expressed as mean \pm SEM, were analyzed statistically using Origin 7.0 software, with paired $t$ tests unless stated otherwise.

As for all slice studies, it is possible that some electrophysiological properties of JG cells differ from those in vivo because of differences in temperature, sensory input, and neurochemical milieu.

\section{Results}

Recordings were obtained from single or pairs of JG neurons. For whole-cell recordings, cells were simultaneously filled with Lucifer yellow for real-time visualization and biocytin for post hoc morphological analysis. JG neurons were classified morphologically as ET, SA, or PG cells on the basis of previous studies (Pinching and Powell, 1971a,b; Aungst et al., 2003; Hayar et al., 2004). The electrophysiological properties of JG neurons were evaluated within a few minutes immediately after going into the whole-cell configuration, to minimize potential run-down effects (Hayar et al., 2004). All neurons recorded were capable of generating action potentials.

\section{ET cells spontaneously generate rhythmical bursts of action potentials}

The morphological and physiological properties of ET cells have been detailed recently (Hayar et al., 2004) and are summarized briefly here to provide an entrée to the present experiments. ET cells have relatively large somata (area $\left.=88 \pm 8 \mu \mathrm{m}^{2} ; n=25\right)$, a resting membrane potential of $-53 \pm 1 \mathrm{mV}$, and an input resistance of $194 \pm 32 \mathrm{M} \Omega(n=12)$. Morphologically, they are characterized by a primary dendrite with a tuft-like arborization that ramifies extensively in a single glomerulus (Figs. $1 A, 2 A$; see Figs. $4 A 3,5 A, B)$ and a single axon that exits the glomerular layer and courses toward the subjacent external plexiform layer. The most distinctive physiological characteristic of ET cells is that they spontaneously generate rhythmical bursts of action potentials in the theta frequency range $(3.3 \pm 0.2$ bursts/sec; range, 
$0.5-8.8$ bursts/sec; $n=110$ ) (Fig. $1 F$ ). The bursts consist of clusters of two or more action potentials riding on a distinct slow depolarizing envelope $(6.3 \pm 0.4 \mathrm{mV}$ in amplitude; $101 \pm 7.6 \mathrm{msec}$ in duration; $n=26)$. Bursting in ET cells is attributable to voltage-dependent intrinsic membrane properties and does not require synaptic input (Hayar et al., 2004).

\section{PG and SA cells}

The morphological characteristics of PG cells $(n=33)$ (Figs. $1 B, 2 C, D)$ and SA cells (Figs. $1 C, 2 B)(n=11)$ were distinct from ET cells. PG cells have a relatively small soma (mean, $47 \pm 10 \mu \mathrm{m}^{2}$ ). They had either one to three relatively thick primary dendritic shafts giving rise to thinner branches that ramify within a single glomerulus or several very thin dendrites that ramify close to the soma. Spines were present on $60 \%$ of PG cells. SA cell bodies averaged $90 \pm 16 \mu \mathrm{m}^{2}$; they have three to five $(3.2 \pm 0.3)$ poorly branched dendrites that contact two to four glomeruli. The most prominent anatomical feature of SA cells $(n=11)$ was their axonal arbor, characterized by relatively thin axons $(<0.5$ $\mu \mathrm{m}$ diameter) that ramified up to $850 \mu \mathrm{m}$ exclusively within the glomerular layer. A more detailed description of SA cells has been reported recently (Aungst et al., 2003).

The physiological properties of $\mathrm{PG}$ and SA cells also differed from ET cells. PG cells had resting membrane potentials ranging from -69 to $-62 \mathrm{mV}(-65 \pm 2$ $\mathrm{mV} ; n=48)$. Their input resistance $(1054 \pm 106 \mathrm{M} \Omega ; n=48)$ was significantly higher than ET cells ( $p<0.05$; unpaired $t$ tests). SA cells had resting membrane potentials of $-62 \pm 1.3 \mathrm{mV}$ and a mean input resistance of $642 \pm 114 \mathrm{M} \Omega$. PG and SA cells had very different spontaneous (Fig. $1 B, C$ ) and current-induced activity from ET cells. In contrast to the spontaneous rhythmic bursting of ET cells, PG and SA cells seldom generated spontaneous action potentials. Intracellular injection of depolarizing current in SA and PG cells induced single action potentials; further depolarization caused regular firing and eventually spike inactivation, but never rhythmic bursting. A small number of PG cells (7\%; data not shown) responded to brief depolarizing current pulses with a sustained "plateau potential" that outlasted the depolarizing current pulses. Current injections never elicited slow, rhythmic depolarizations such as those in ET cells, suggesting that SA and PG cells lack the intrinsic capacity to generate rhythmic bursting.
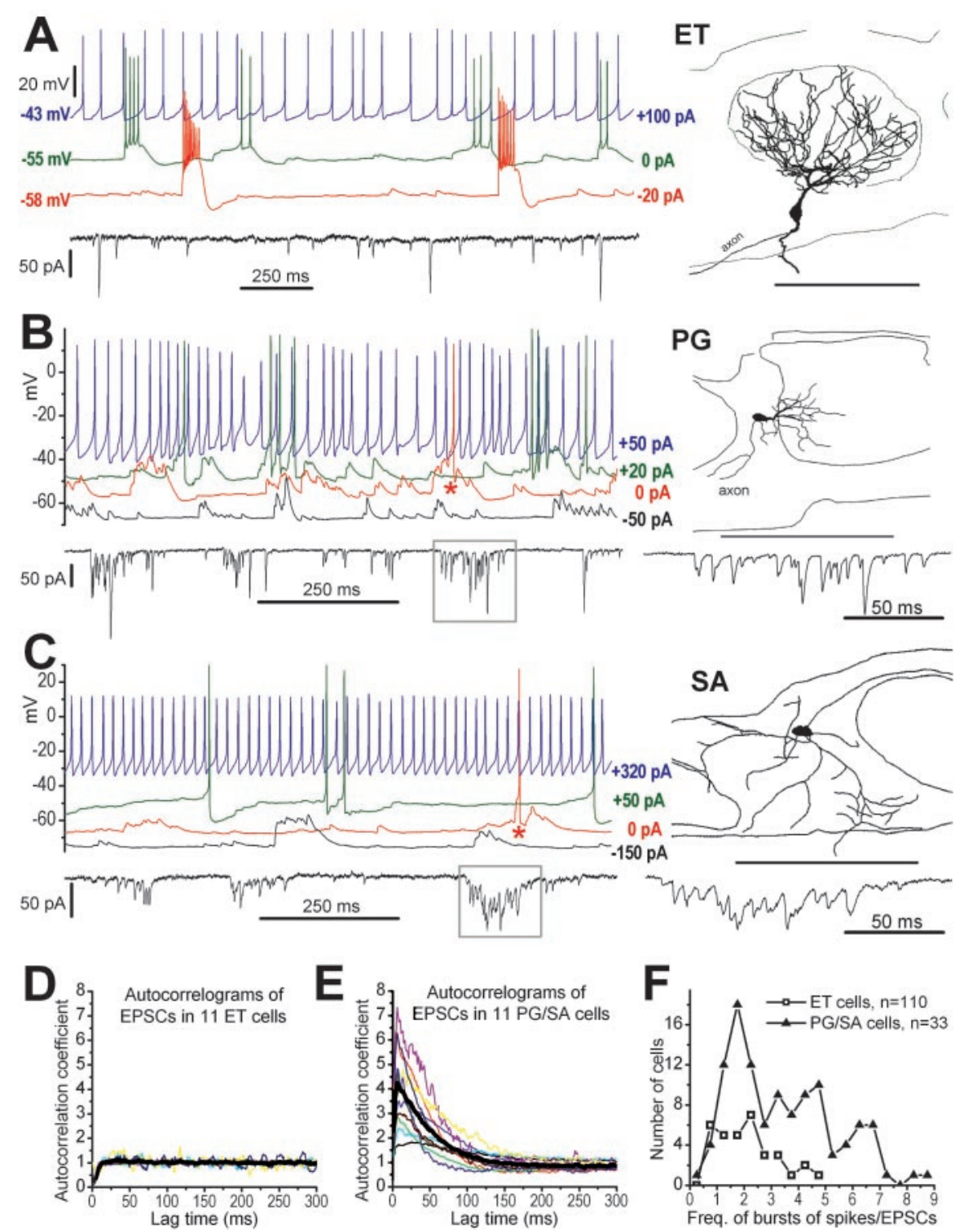

Figure 1. ET neurons generate rhythmical spike bursts, whereas PG and SA cells receive spontaneous bursts of excitatory synaptic input. $A$, Recordings from an ET cell in whole-cell configuration. Inset at right shows the morphology of the recorded ET cell. Note the highly branched tufted dendrites that ramify throughout a single glomerulus. Thin lines above and below the glomerular layer (GL) in this and subsequent figures indicate boundaries of the GL with the ON layer (ONL) and external plexiform layer (EPL), respectively. ET cell burst rate is voltage dependent. Current-clamp recordings show effects of steady hyperpolarizing or depolarizing current injection on bursting activity. Spontaneous activity at rest $(0 \mathrm{pA})$ is characterized by spike bursts riding on a slow depolarizing envelope. Hyperpolarizing current $(-20 \mathrm{pA})$ reduced the burst frequency and increased the number of spikes per burst. Irregular firing was produced with more positive current injection $(+100 \mathrm{pA})$. Bottom trace, Voltage-clamp recording [holding potential $(\mathrm{HP})=-60 \mathrm{mV}$ ] of the same cell showing spontaneous EPSCs of varying amplitudes. Note that ET cells receive isolated short-duration EPSCS. B, Top traces, Current-clamp recordings show effects of steady hyperpolarizing or depolarizing current injection in a typical PG cell. At rest $(0 \mathrm{pA})$ the cell receives spontaneous long-duration bursts of EPSCs and generates spikes infrequently, notably during bursts of EPSPs (asterisk). The cell did not generate spike bursts after depolarizing or hyperpolarizing current injection. Reconstruction of the recorded cell at left shows typical morphology of PG cells, including relatively small soma and one to three relatively thick primary dendritic shafts that give rise to thinner branches ramifying within a subregion of a single glomerulus. Bottom traces, Voltage-clamp recording ( $\mathrm{HP}=-60 \mathrm{mV}$ ) shows bursts of spontaneous EPSCs in the same PG cell; region enclosed in the box is shown at faster time scale at right. $C$, The resting activity of $S A$ cells and their responses to current injection were similar to PG cells. Note also that SA cells receive bursts of spontaneous EPSCs. Reconstruction of the recorded cell at left shows typical morphology of SA cells, including several poorly branched dendrites extended into or between two to four glomeruli. Scale bars, $100 \mu \mathrm{m}$. D, E, Superimposed autocorrelograms (bin = $1 \mathrm{msec}$; smoothed with 3 points adjacent averaging; events recorded in 2-10 min) of spontaneous EPSC trains in ET cells $(D)$ and PG/SA cells $(E)$. Thick black lines represent the mean autocorrelograms. The mean autocorrelogram in a PG/SA cell had a decay time constant $(\tau)$ of $53 \mathrm{msec}$. $F$, Distribution of the frequencies (bin $=0.5$ burst/sec) of bursts of spikes in ET cells and the frequencies of bursts of EPSCs in PG/SA cells. 


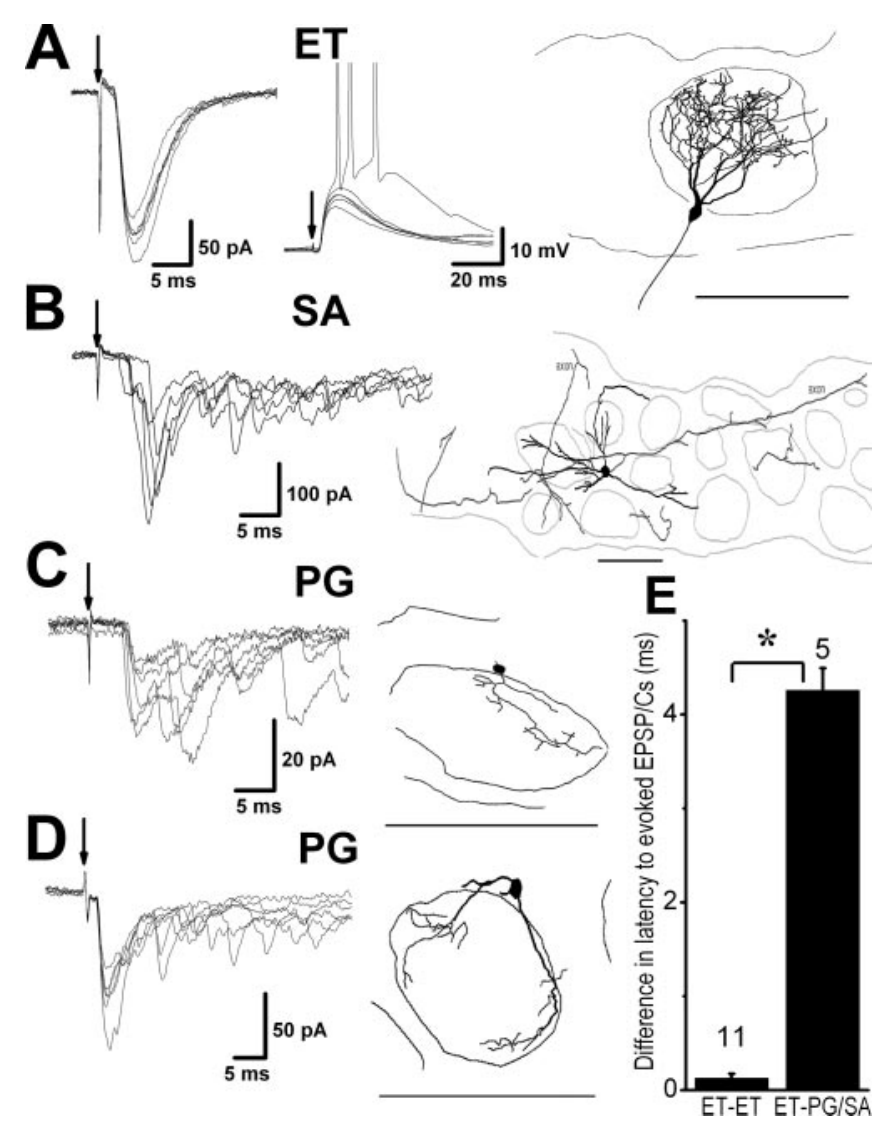

Figure 2. Sensory-evoked synaptic responses of the four JG cell subtypes. $A-D$, Superimposed voltage-clamp traces ( $\mathrm{HP}=-60 \mathrm{mV}$ in $A-D)$ of $0 \mathrm{~N}$-evoked EPSCs in ET, SA, and two PG cells. Arrows indicate time of stimulation. Cell morphology is shown at right. Scale bars, 100 $\mu \mathrm{m}$. ON stimulation produced short constant latency EPSCs in the ET cell ( $A$, left panel), indicative of monosynaptic input. In current clamp, $0 \mathrm{~N}$ stimulation evoked constant short-latency EPSPs of variable amplitude (A, middle panel). The largest EPSPs triggered the generation of a burst of action potentials (truncated for clarity). $B$ and ( show that $0 \mathrm{~N}$ stimulation evoked longer variable-latency EPSCs bursts in SA ( $B$ ) and PG ( $C$ ) cells, indicative of disynaptic or poly-synaptic responses. The $P G$ cell in $D$ differed from the other cell types by responding with a constant latency EPSC followed by a burst of EPSCS. E, Grouped data from simultaneous recordings showing a significant difference $\left({ }^{*} p<0.05\right.$; unpaired $t$ test $)$ in $0 \mathrm{~N}$-evoked EPSP or EPSC onset latency between $E T-E T$ and $E T-P G / S A$ cell pairs. The numbers above the columns correspond to the number of recorded pairs.

\section{Spontaneous excitatory synaptic events in JG cells}

The most distinctive feature of the spontaneous activity of SA and PG cells was that they exhibited bursts of EPSPs or EPSCs. Eightsix percent of cells in a random sample $(n=14 ; 5$ of 6 SA cells and 7 of 8 PG cells) exhibited spontaneous bursts of EPSPs or EPSCs; the remaining SA and PG cells (2 of 14) exhibited single EPSPs or EPSCs. Accordingly, the bursting mode of spontaneous synaptic activity was so characteristic for PG and SA cells that it was virtually diagnostic for distinguishing them from ET cells. In current clamp, the EPSP bursts sometimes triggered one or a few action potentials (Fig. $1 B, C$ ). In voltage clamp, bursts were defined as a cluster of four or more EPSCs occurring at a frequency of $>100 \mathrm{~Hz}$. On average, spontaneous synaptic bursts consisted of $14.1 \pm 1.6$ EPSCs (range, 5-47 EPSCs; $n=33$ cells) and occurred at a rate of $2.0 \pm 0.2$ bursts/sec (range, $0.5-4.5$ bursts/sec; $n=33$ cells). The mean EPSC frequency in PG/SA cells was $22.1 \pm 2.0 \mathrm{~Hz}$. In contrast, in ET cells only individual, randomly occurring EPSCs were observed. The difference in the pattern of spontaneous EPSCs in PG/SA versus ET cells was evident in autocorrelograms (Fig. 1, compare D, E). The EPSCs in PG/SA cells exhibited a significant autocorrelation coefficient (see Materials and Methods) with a mean peak of $4.3 \pm 0.5$ (range, $1.8-7.3 ; n=$ $11)$, whereas the autocorrelation coefficient did not reach significance in ET cells ( $1.3 \pm 0.1$; range, $1.1-1.6 ; n=11)$. The frequencies of EPSC bursts in PG/SA cells overlapped with the lower half of the frequency range of spike bursts in ET cells (Fig. $1 F$ ), suggesting a correlation between spike bursts in ET cells and EPSC bursts in PG/SA cells.

\section{Olfactory nerve synaptic input to JG cells}

Because all three JG cell types have dendritic arbors within glomeruli, it is possible that they receive input from ON terminals. To investigate this, we first recorded the responses of ET cells to ON activation in voltage-clamp mode. In all 24 ET cells tested, ON stimulation evoked a single EPSC with an onset latency of $2.1 \pm 0.05 \mathrm{msec}$ (Fig. 2A, left panel). ON-evoked EPSC onset latency was remarkably constant across all ET cells, with a mean SD of $87 \pm 9 \mu \mathrm{sec}$ (range, $52-115 \mu \mathrm{sec} ; n=8$ cells). The coefficient of variation $(\mathrm{CV}=\mathrm{SD} /$ mean $)$, a measure of trial-to-trial variability of the evoked EPSC onset latency, was very low (0.04) in these cells. The short, invariant latency of the responses to $\mathrm{ON}$ stimulation suggests that the ET cells receive monosynaptic ON input (Doyle and Andresen, 2001). In current-clamp recordings, perithreshold intensity stimuli elicited either a single, constant latency subthreshold EPSP or a suprathreshold EPSP that generated a burst of action potentials (Fig. $2 \mathrm{~A}$, middle panel). Thus, ON-evoked spike bursts in ET cells, like the spontaneous bursts in these cells (Hayar et al., 2004), are all-or-none in nature.

ON stimulation evoked relatively long and variable latency bursts of EPSPs or EPSCs in all SA cells tested $(n=18)$ (Fig. $2 B$ ). The onset latency of the first evoked EPSP or EPSC in SA cells was significantly longer $(6.1 \pm 0.4 \mathrm{msec} ; n=12 ; p<0.0001$; unpaired $t$ test $)$ and 18 -fold more variable $(\mathrm{SD}=1.57 \pm 0.35 \mathrm{msec}$; range, $0.40-3.3 \mathrm{msec} ; n=8 ; p<0.001)$ than that in ET cells. The CV for the ON-evoked onset latency (0.26) was six times higher than in ET cells. These observations indicate that SA cells do not receive monosynaptic input from the ON.

PG cells had mixed responses to ON stimulation. One population $(79.7 \% ; n=47$ of 59 cells) responded with relatively long $(5.5 \pm 0.56 \mathrm{msec}$ ) (Fig. $2 \mathrm{C})$ and variable latency EPSCs; the SD of the latency was $3.8 \mathrm{msec}$ and the $\mathrm{CV}$ was 0.69 . A second population of PG cells $(20.3 \% ; n=12$ of 59 cells) responded at short, constant latency $(2.3 \pm 0.18 \mathrm{msec})$ to $\mathrm{ON}$ stimulation with a synaptic "jitter" of $<300 \mu \mathrm{sec}$, consistent with monosynaptic input (Fig. 2D) (Doyle and Andresen, 2001). In 9 of these 12 "monosynaptic" PG cells, the short-latency EPSC was followed by a burst of EPSCs consistent with a disynaptic or polysynaptic input. Taken together, these results indicate that ET cells receive monosynaptic input from ON terminals, whereas SA and the majority $(\sim 80 \%)$ of PG cells have disynaptic or polysynaptic responses to ON input. Some (15.2\%; 9 of 59 cells) PG cells receive both monosynaptic and polysynaptic $\mathrm{ON}$ input, and a few $(\leq 5 \%)$ receive only monosynaptic ON input. The proportion of PG cells that receive monosynaptic ON input $(\sim 20 \%)$ could be somewhat underestimated, however, because PG cells have sparse dendrites that occupy a restricted portion of a glomerulus and may be more prone than ET cells to loss of ON synaptic input because of truncation in the in vitro slice.

\section{ET cells provide excitatory input to $\mathrm{PG}$ and SA cells}

The finding that ET cells fire rhythmic bursts of spikes whereas PG/SA cells exhibit spontaneous and ON-evoked bursts of EPSCs is consistent with the hypothesis that ON synapses excite ET cells, 

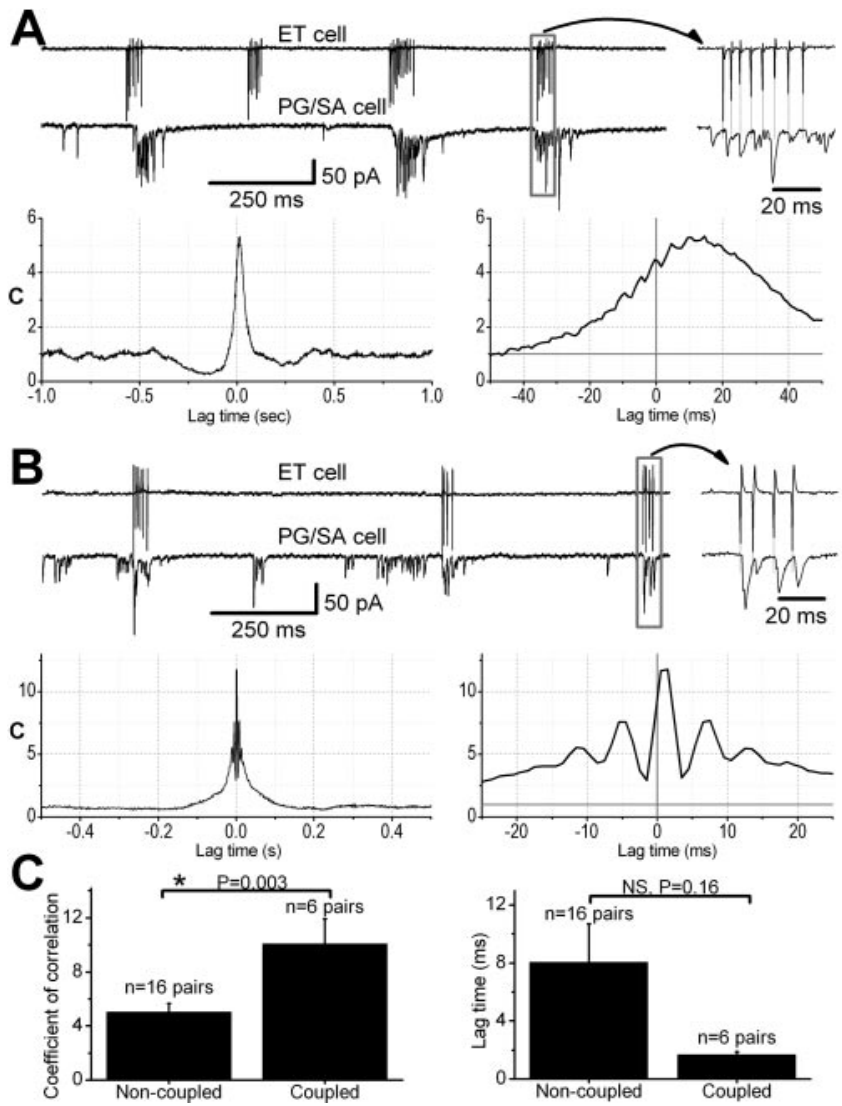

Figure 3. Temporal correlations between ET cell spike bursts and PG/SA cell EPSC bursts. Simultaneous extracellular recordings from a rhythmically bursting $E T$ cell $(A, B$, top traces) and whole-cell voltage-clamp recording ( $\mathrm{HP}=-60 \mathrm{mV}$ ) from a presumed $\mathrm{PG} / \mathrm{SA}$ cell exhibiting spontaneous bursts of EPSCS ( $A, B$, bottom traces). $A$, Nonsynaptically coupled ET-PG cell pair. Note the temporal correspondence between spike and EPSC bursts in the two cells; area in the rectangle is shown at faster time scale at right. The left cross-correlogram (bin size $=1 \mathrm{msec}$ ) of spike and EPSC trains shows significant correlated activity (coefficient of correlation $=5.2$ ) between the two cells. The same cross-correlogram, shown at faster time scale on the right, illustrates that the probability of occurrence of EPSCs in the $\mathrm{PG} / \mathrm{SA}$ cell is maximal $\sim 10 \mathrm{msec}$ after the occurrence of the spikes in the ET cell. B, Synaptically coupled ET-PG pair. Inset (at right) of recording at faster time scale shows that each spike in the ET cell is associated with an individual short-latency ( $\sim 1 \mathrm{msec})$ EPSC in the $\mathrm{PG} / \mathrm{SA}$ cell. The cross-correlogram shows a significant coefficient of correlation with a sharp peak $(C=11.8)$ at a lag time of $\sim 1$ msec. $C$, The peak coefficient of correlation was significantly higher $(p<0.005)$ in synaptically coupled $E T-P G / S A$ pairs compared with nonsynaptically coupled pairs.

which in turn make excitatory synapses onto PG/SA cells. If correct, then spikes in ET cells should be correlated with EPSCs in PG/SA cells. To investigate this, we recorded spontaneous EPSCs from a PG/SA cell $(n=19)$ in whole-cell voltage-clamp mode while sequentially recording extracellularly (cell-attached mode) spontaneous spike bursts from six to eight nearby ET cells. Spontaneous activity patterns monitored on-line indicated that up to six ET cells (mean $=$ three cells) had spike bursts that appeared to be correlated with the bursts of EPSCs in the PG/SA cell. The strength and temporal association of correlated activity was assessed off-line using cross-correlation and spike-triggered averaging analyses for 22 of 62 randomly selected ET-PG/SA pairs. As detailed next, these analyses revealed two distinct activity patterns among correlated ET-PG/SA cell pairs.

For 16 of 22 ET-PG/SA pairs, analysis of cross-correlograms revealed a broad range of correlated spontaneous activity (spikes and EPSCs) without a sharp peak, suggesting a variable latency between ET cell spikes and PG/SA cell EPSCs (Fig. 3A). Analysis of cross-correlograms yielded a peak $C$ value of $5.0 \pm 0.64$ (range, $2.3-9.0 ; n=16$ ) at a mean lag time of $8.0 \pm 2.6 \mathrm{msec}$ (range, $0-35$ $\mathrm{msec}$ ). In these same pairs, spike-triggered averages of EPSCs in PG/SA cells lacked a sharp peak. These findings suggest that activity among some ET-PG/SA cell pairs is strongly correlated but is not mediated by monosynaptic coupling; we refer to such pairs as correlated but nonsynaptically coupled.

In the remaining six ET-PG/SA pairs, there was a sharp peak in their cross-correlograms at a short lag time of $<2 \mathrm{msec}$ (i.e., first or second $1 \mathrm{msec}$ bin) (Fig. $3 B$ ). The peak coefficient of correlation, $C=10.0 \pm 1.8$, in these ET-PG/SA pairs was significantly higher $(p<0.005$; unpaired $t$ test $)$ compared with the nonsynaptically coupled pairs (Fig. $3 C$ ). Spike-triggered averages in such pairs exhibited a sharp, short-latency peak (Fig. 4C, left); the latency between the spike in the ET cell and the EPSC in the PG/SA cell was $0.85 \pm 0.05 \mathrm{msec}$, consistent with monosynaptic input (Feldmeyer et al., 1999). If ET cells provide monosynaptic excitatory input to PG/SA cells, then spikes evoked in the ET cell should elicit short-latency EPSCs in the PG/SA cell. To test this, we delivered current pulses $(0.5-0.7 \mathrm{nA} ; 100 \mathrm{msec})$ through the recording pipette to evoke action potentials in the ET cell. In all six cell pairs, evoked ET cell spikes were followed by EPSCs in the SA/PG cells at a latency of $0.85 \pm 0.05 \mathrm{msec}$ (Fig. $4 C$, right). Individual ET cell spikes appeared to trigger single EPSCs in PG/SA cells (Fig. 4C), although occasionally the first spike in a burst failed to trigger an EPSC.

\section{ET cells provide intraglomerular, glutamatergic input to $P G$ and SA cells}

The preceding analysis suggested that $\sim 27 \%$ ( 6 of 22 ) of ETSA/PG cells pairs are monosynaptically coupled; however, because the methodology used, i.e., searching for bursting cells with extracellular recordings did not allow us to determine whether ET-PG/SA cell pairs were in the same glomerulus, the degree of synchrony among JG cells of the same glomerulus may have been underestimated. To investigate this, we made dual, whole-cell recordings from ET-PG/SA cell pairs and filled them with biocytin to confirm their glomerular affiliation (Fig. 4). Five cell pairs (three ET-PG and two ET-SA pairs) associated with the same glomerulus were investigated. We first examined how simultaneously recorded ET and PG/SA cells responded to ON stimulation. Such paired recordings showed that the onset of ON-evoked EPSP or EPSC in PG/SA cells occurs $4.3 \pm 0.2 \mathrm{msec}$ later in PG/SA cells than in ET cells $(p<0.05)$ (Fig. $2 E)$. This value $(4.3$ $\mathrm{msec}$ ) is consistent with the difference in the mean latencies of the ON-evoked EPSCs in ET cells $(2.1 \mathrm{msec})$ and PG/SA cells (5.5$6.1 \mathrm{msec}$ ) when these cells were recorded individually (see above results). In contrast, ET cells always responded simultaneously when recorded in pairs, i.e., the time interval between the two EPSC onset latencies is near zero msec (Fig. 2E).

For all five ET-PG/SA cell pairs, spontaneous bursts of spikes in the ET cell were significantly cross-correlated with the bursts of EPSPs in the PG or SA cell (membrane potential crosscorrelation coefficient $C_{\mathrm{m}}=0.50 \pm 0.06$ ) (Fig. $4 A, B$ ). For three pairs, activity was highly correlated, but spike-triggered averaging did not indicate that the pairs were monosynaptically coupled, similar to the results for the nonsynaptically coupled pairs recorded extracellularly above (data not shown). For the other two of the five same-glomerulus pairs, spike-triggered averaging showed that EPSPs in the PG/SA cell occurred $0.85 \mathrm{msec}$ after an action potential in the ET cell (Fig. 4B3), consistent with monosynaptic activation of the PG/SA cell by the ET cell (Feldmeyer et al., 1999). Thus, when ET-SA/PG cells are confirmed to be asso- 

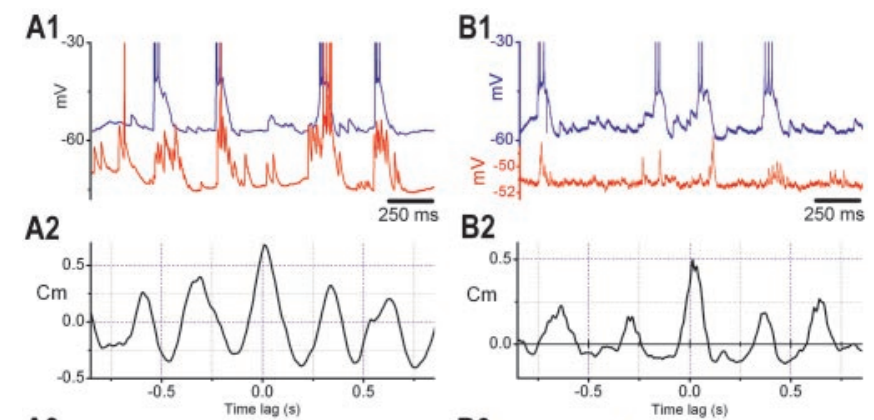

A3
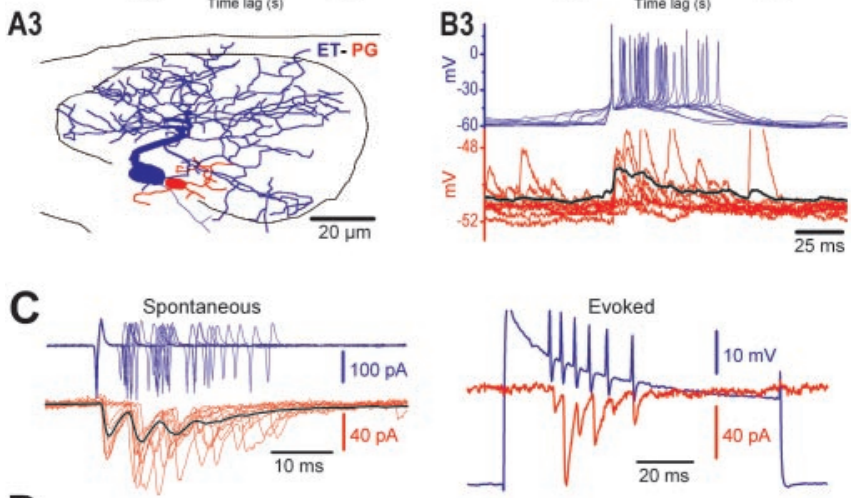

D
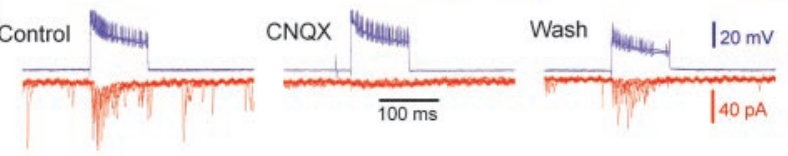

Figure 4. ET cells provide excitatory synaptic input to PG and SA cells. A1-A3, Simultaneous whole-cell current-clamp recordings from an $\mathrm{ET}$ cell (blue trace) and a $\mathrm{PG}$ cell (red trace). A1, ET cell spike bursts are closely associated with the bursts of EPSPs in the PG cell. A2, Crosscorrelogram of the membrane potentials of the $E T$ cell to the $P G$ cell reveals synchronous activity with a peak correlation coefficient $\left(C_{\mathrm{m}}\right)$ of 0.67 . $A 3$, Reconstruction shows that both recorded cells ( $E T$, blue; $P G$, red) have dendrites in the same glomerulus. B1-B3, Simultaneous whole-cell current-clamp recordings from an ET cell (blue trace) and a PG cell (red trace) associated with the same glomerulus. B1, ET cell spike bursts are closely associated with the bursts of EPSPs in a $P G$ cell. $B 2$, Cross-correlogram of the membrane potentials of the ET cell to the PG cell reveals synchronous activity with a peak $C_{\mathrm{m}}$ of 0.49 . $B 3$, Burst-triggered averaging demonstrates that ET cell bursts (blue superimposed traces, triggered on the first spike in the burst) evoke shortlatency bursts of EPSPs in the PG cell (red traces; black line is the average of 17 traces). The latency from the peak of the first ET cell spike to the onset of the averaged evoked EPSP is 0.85 msec. C, Dual recordings from an ET cell in cell-attached mode (blue traces) and a PG/SA cell in whole-cell voltage-clamp mode (red traces). Left panel (Spontaneous) shows 10 superimposed spontaneous spike burst-triggered traces (triggered on the first spike in the burst); black line is the average of 135 similar traces. Note that spontaneous action currents (blue trace) are accompanied by phase-locked busts of EPSCS (red trace). Right panel (Evoked) shows an example of a burst of EPSCS (red trace) evoked by a burst of spikes elicited by extracellular injection of a positive current pulse (700 pA; $100 \mathrm{msec})$. Note close correspondence between evoked spikes in the ET cell and EPSCs in the SA/PG cell. D, Recordings from the same two cells shown in (before (Control), during, and after (Wash) application of CNQX (10 $\mu \mathrm{M})$. Note that bursts of EPSCs (red traces) in the SA/PG cell elicited by current injection-evoked spikes (blue traces) in the ET cell are completely blocked by CNQX (middle) in a reversible manner (right). CNQX also reversibly abolished spontaneous EPSCS. All panels show five superimposed sweeps.

ciated with the same glomerulus, the percentage of synaptically coupled cells is higher [ $40 \%$ (two of five pairs)] than the $27 \%$ obtained by the extracellular recording. In contrast, six ETPG/SA pairs with dendrites that were in different glomeruli exhibited no significant cross-correlation in their membrane potentials (data not shown). These results indicate that JG cells in the same glomerulus have highly correlated spontaneous activity. They further suggest that synchrony among JG cells of the same glomerulus is mediated, at least in part, by monosynaptic excitatory input from ET cells to PG and SA cells.
Finally, we investigated the neurotransmitter involved in the ET-PG/SA cell monosynaptic relationship. Dual ET-PG/SA cell recordings were made as in the preceding experiment. The PG/SA cell was recorded in whole-cell voltage-clamp mode to record EPSCs. Cell-attached recordings were used to locate an ET cell for which spontaneous and current-evoked bursts of action potentials preceded EPSCs in the PG/SA cell by $<1 \mathrm{msec}$, indicative of a monosynaptic relationship (Fig. 4C). Next, the AMPA-kainate receptor antagonist CNQX was applied, and spike bursts were again evoked in the ET cell. In all such cases ( $n=4$ pairs), ET cell-evoked bursts of EPSCs in SA and PG cells were entirely and reversibly blocked by CNQX (Fig. 4D); spontaneous EPSCs in PG/SA cells were also abolished by CNQX. Taken together, these results demonstrate that ET cells provide monosynaptic, glutamatergic, ionotropic receptor-mediated input to SA/PG cells.

\section{ET cells of the same glomerulus have correlated activity}

The preceding results show that a single ET cell spike generates, at most, a single EPSC in a simultaneously recorded, monosynaptically coupled PG/SA cell; however, the number of EPSCs in spontaneously occurring EPSCs bursts in PG/SA cells calculated previously (mean, 14.1) (Fig. $3 A, B$, top traces) typically exceeds the mean number of spikes in spontaneous ET cell bursts [average $5.4 \pm 0.3$ spikes per burst; $n=72$ cells (Hayar et al., 2004)]. This suggests that $\mathrm{PG} / \mathrm{SA}$ cells receive convergent monosynaptic input from multiple ET cells that had correlated activity. This hypothesis is also consistent with the previous finding that the spontaneous activity of multiple ET cells was correlated with that of an individual PG/SA cell. Because of their extensive dendritic ramifications throughout a single glomerulus, ET cells may interact to generate correlated activity, as do mitral cells having dendrites that terminate in the same glomerulus (Carlson et al., 2000; Schoppa and Westbrook, 2001, 2002; Urban and Sakmann, 2002).

To investigate possible interactions among ET cells, we performed dual whole-cell recordings from 17 ET-ET cell pairs and constructed cross-correlograms of their membrane potentials (see Materials and Methods). The cells were filled with biocytin so that the glomerular affiliation of each cell could be determined by post hoc morphological analysis. Six of $17 \mathrm{ET}$ cell pairs had dendrites that ramified in the same glomerulus (Fig. 5). All six sameglomerulus pairs had significantly correlated activity (peak $C_{\mathrm{m}}=$ $0.54 \pm 0.02$; range, $0.27-0.73$; peak lag time $=0-10 \mathrm{msec}$ ) (Fig. $5 A$ ). In contrast, activity was not significantly correlated in 7 of 11 ET cell pairs associated with different glomeruli. In the other 4 of 11 different-glomerulus pairs, membrane potentials were correlated $\left(C_{\mathrm{m}}=0.44 \pm 0.06\right.$; range, $\left.0.36-0.61\right)$, but with a long time lag (115 \pm 19 msec; range, $62-150 \mathrm{msec}$ ) (Fig. $5 B)$. Because we have shown recently that SA cells synaptically contact JG cells across glomeruli over long distances (up to $1 \mathrm{~mm}$ ) (Aungst et al., 2003), it is possible that SA cells coordinate activity among ET cells in different glomeruli.

Correlated activity could arise from common excitatory inputs to ET cells of the same glomerulus. To investigate this possibility, we measured correlated activity (filtered membrane potential after spike truncation; see Materials and Methods) before and after adding a mixture of fast synaptic blockers (CNQX, 10 $\mu \mathrm{M}$; APV, $50 \mu \mathrm{M}$; gabazine, $10 \mu \mathrm{M})$. In three of three sameglomerulus ET cell pairs, correlated membrane potentials persisted, and in fact increased, in the presence of fast synaptic blockers (control: $C_{\mathrm{m}}=0.62 \pm 0.2$; blockers: $C_{\mathrm{m}}=0.71 \pm 0.3 ; p<$ 0.05) (Fig. 5A). Thus, although fast synaptic transmission might be involved in setting the precise timing of burst occurrence in 


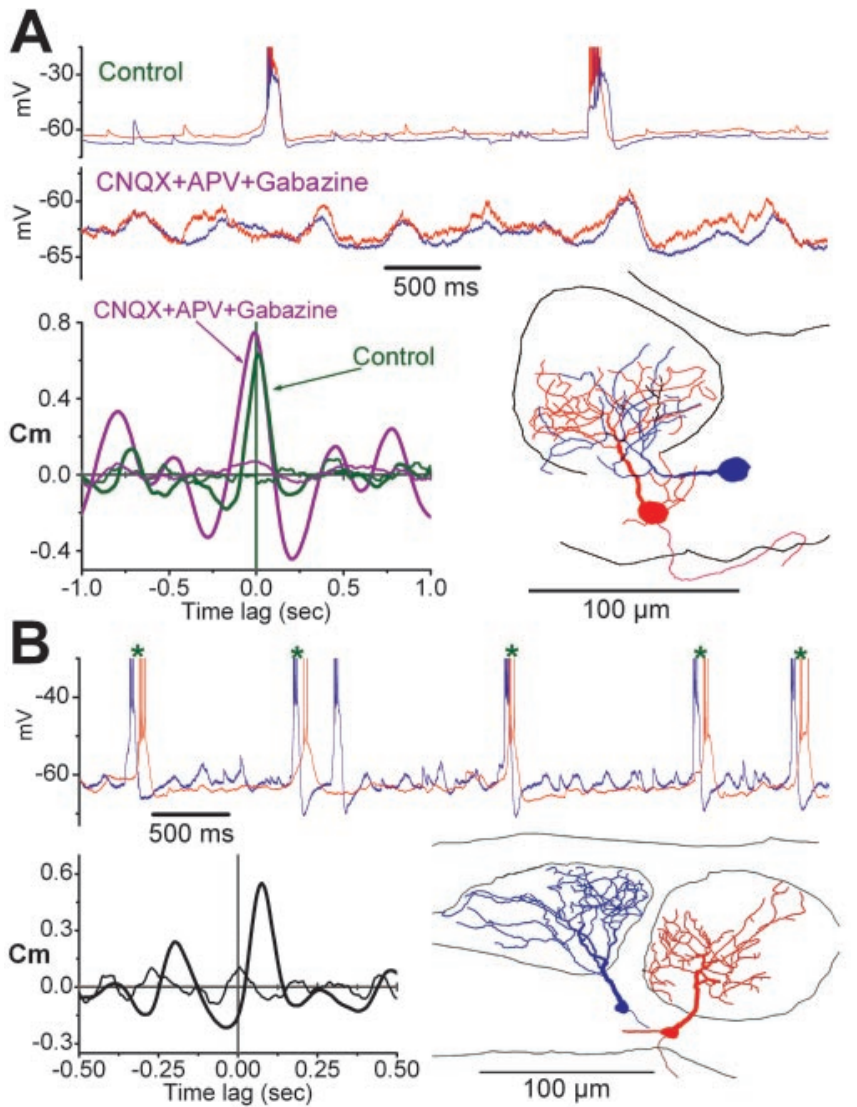

Figure 5. Activity among ET cells of the same glomerulus is highly correlated. A, Dual wholecell current-clamp recording from two ET cells (red and blue traces, respectively) showing correlation of spike bursts and membrane potentials. Reconstruction of the recorded cells at bottom right panel shows that the dendrites of both cells ramify in the same glomerulus. The cross-correlograms at bottom left show that the synchronous membrane potential oscillations of the two cells (green cross-correlogram; Control) persist and are slightly enhanced during application of the fast synaptic blockers (pink cross-correlogram; CNQX + APV + Gabazine). $B$ Two ET cells that ramify in adjacent glomeruli (drawn in bottom right panel) also exhibited correlated bursting but with a long delay between the occurrence of bursts (asterisks). The peak of the cross-correlation $\left(C_{m}=0.55\right)$ occurred at a time lag of $70 \mathrm{msec}$. Thin lines in the crosscorrelograms represent the corresponding shuffled cross-correlations (see Materials and Methods). Spikes were truncated in all panels to emphasize membrane potential oscillations.

correlated ET cell pairs, it is not essential for maintaining their correlated activity.

ET cells spontaneously generate bursts of action potentials riding on distinct slow depolarizing membrane potentials. Because membrane potentials among same-glomerulus ET cells are correlated, we asked whether spike bursting is correlated. It was not possible to correlate bursting in whole-cell recording because bursting undergoes rundown, and spontaneous bursting stops in ET cells within $2-15$ min (mean, $7.2 \pm 1.9$ min; $n=6$ cells) after whole-cell configuration is established (Hayar et al., 2004). Because ET cells are the only JG cells that exhibit spontaneous bursting, however, they are readily identified in extracellular recordings in which recording configuration their activity is stable. Thus, we obtained long-term ( $>5 \mathrm{~min})$ extracellular recordings from 24 ET cell pairs $(<100 \mu \mathrm{m}$ apart) having bursts that appeared to coincide on-line. For these pairs, the mean peak of the spike train cross-correlation coefficient $(C)$ (see Materials and Methods) was $4.2 \pm 0.7$ (range, 1.3-15.5), with a mean time lag of $20 \pm 5 \mathrm{msec}$ (range, $0-105 \mathrm{msec}$ ). As with the whole-cell recordings, correlated bursting activity was maintained and, indeed, enhanced in the presence of fast synaptic blockers $(n=14$; con-
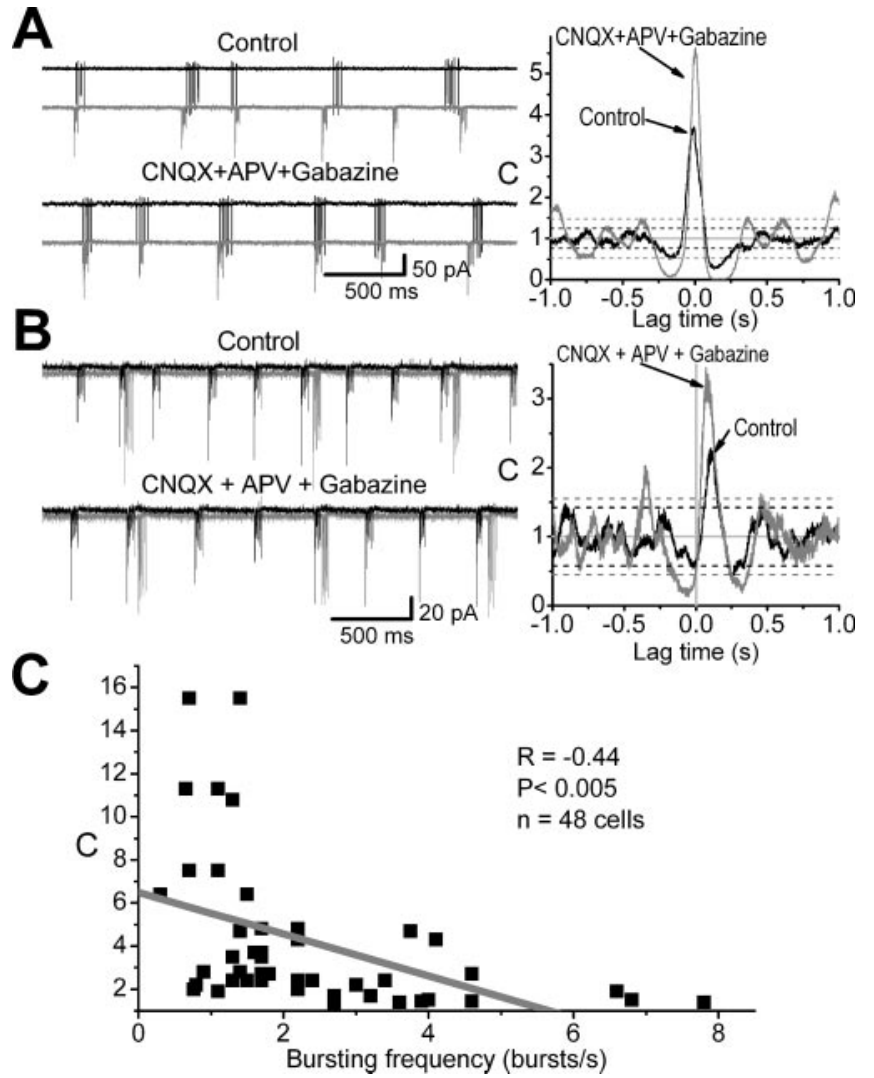

Figure 6. Correlated bursting among ET cells persists during blockade of fast synaptic transmission. $A, B$, Simultaneous extracellular recordings from two different $E T$ cell pairs, illustrating spontaneous spike bursts before and during application of fast synaptic blockers. Blockade of fast synaptic transmission increases the degree of synchrony as shown in the crosscorrelograms (right panel). Dashed horizontal black and gray lines in the cross-correlograms indicate the corresponding $99.97 \%$ confidence limit. Note that in B the two correlated cells have different bursting frequencies. In the presence of synaptic blockers, the time of the peak of correlation was $3 \mathrm{msec}(A)$ and $77 \mathrm{msec}(B)$, respectively. C, Scatter plot showing the peak of correlations $(C)$ as a function of the bursting frequency of the correlated ET cells. The linear regression fit (gray line) indicates that the strength of the correlation is smaller in cells bursting at relatively high frequencies.

trol: $C=3.8 \pm 0.9$ vs synaptic blockers: $C=6.9 \pm 2.0 ; p<0.05)$ (Fig. 6A,B). Thus, unlike mitral cells (Carlson et al., 2000), correlated activity among ET cells does not require activation of glutamatergic or GABAergic ionotropic receptors. It is possible that ET cells of the same glomerulus communicate via gap junctions as has been suggested for mitral cells (Schoppa and Westbrook, 2002).

There was no significant correlation $(r=-0.3 ; p=0.2)$ between the peaks of the cross-correlations and the difference in the mean bursting frequencies for cells in a given pair (mean, $1.3 \pm$ 0.3 bursts/sec; range, $0.1-5.5$ bursts/sec; $n=24$ pairs). Thus, ET cells need not have similar bursting frequencies to have significantly correlated bursting (Fig. $6 B$ ). $C$ values, however, were negatively correlated with the bursting frequency $(n=48$ cells; $r=$ $-0.44 ; p=0.001$ ) (Fig. 6C). Thus, correlated bursting was higher among ET cells with relatively low burst frequencies. This suggests that coupling, whatever the mechanism(s), is stronger among slow bursting ET cells of the same glomerulus. A similar frequency-dependent synchrony was reported in pairs of locus coeruleus neurons in adult rats and was attributed to a weak gap-junctional coupling (Alvarez et al., 2002). 


\section{Discussion}

The present results taken with two other recent studies (Aungst et al., 2003; Hayar et al., 2004) show that each glomerulus contains three populations of morphologically and functionally distinct juxtaglomerular neurons: ET, PG, and SA cells. ET cells receive direct $\mathrm{ON}$ input and in turn provide intraglomerular monosynaptic excitatory input to many SA and PG interneurons that do not receive direct $\mathrm{ON}$ input. This synaptic arrangement causes rhythmic spike bursts in ET cells to elicit bursts of EPSPs or EPSCs in PG and SA cells of the same glomerulus. Activity among ET cells of the same but not different glomeruli is highly correlated even in blockers of synaptic transmission. Thus, the glomerular circuitry may amplify (Hayar et al., 2004) and synchronize ON input to the brain.

\section{Juxtaglomerular neurons and glomerular circuitry}

Although the slice preparation may underestimate the connectivity present in the intact animal, this did not prevent us from delineating the different types of cells and their synaptic arrangement. The morphological characteristics of ET, SA, and PG cells reported here are consistent with classic (Pinching and Powell, 1971a,b) and recent (Aungst et al., 2003) findings. ET cells have a primary dendrite that ramifies extensively in a single glomerulus. PG cells have a relatively small soma with short thin dendrites ramifying within a restricted portion of a single glomerulus. The dendrites of SA cells extend into several neighboring glomeruli and contrary to their "classic" name, "short axon," have axons that extend up to $1 \mathrm{~mm}$ within the glomerular layer (Aungst et al., 2003).

ET cells are characterized by rhythmic spontaneous spike bursts (Hayar et al., 2004; this study). The present experiments show that all ET cells receive monosynaptic ON input and, furthermore, that if the amplitude of an ON-evoked EPSP reaches threshold for spike generation, a spike burst is always triggered. Additional increases in $\mathrm{ON}$ stimulation strength produce the same all-or-none burst. Thus, ET cells receive monosynaptic ON input that is converted into an all-or-none spike burst. Accordingly, ET cells amplify suprathreshold sensory input at the first stage of synaptic transfer in the olfactory system.

The spontaneous and ON-evoked activity patterns of SA and PG cells differ markedly from ET cells. PG and SA cells have relatively low levels of spontaneous spike activity and lack the capacity to generate spike bursts in response to depolarizing currents. The majority of PG cells exhibited longer latency, prolonged bursts of EPSP or EPSCs in response to ON stimulation than ET cells. The long variable latency of these responses is indicative of disynaptic or polysynaptic ON input. Only $20 \%$ of PG cells had short relatively constant latency EPSCs after ON stimulation, and in some of these cells the short-latency synaptic response was followed by a delayed burst of EPSP or EPSCs. SA cells also responded to $\mathrm{ON}$ stimulation with long variable latency and prolonged bursts of EPSPs or EPSCs and never exhibited responses consistent with monosynaptic ON input. These findings indicate that (1) SA cells and most PG cells lack direct ON input and (2) ET cells along with mitral/tufted cells are the major postsynaptic targets of $\mathrm{ON}$ inputs.

Anatomical studies suggest a compartmental organization of the glomeruli, consisting of two subregions, one richly and another poorly targeted by ON terminals (Kosaka et al., 1997; Toida et al., 1998, 2000; Kasowski et al., 1999). Because the present findings indicate that as many as $80 \%$ of all PG cells lack monosynaptic ON input, this suggests that most PG cells are functionally associated with glomerular compartments lacking ON termi-

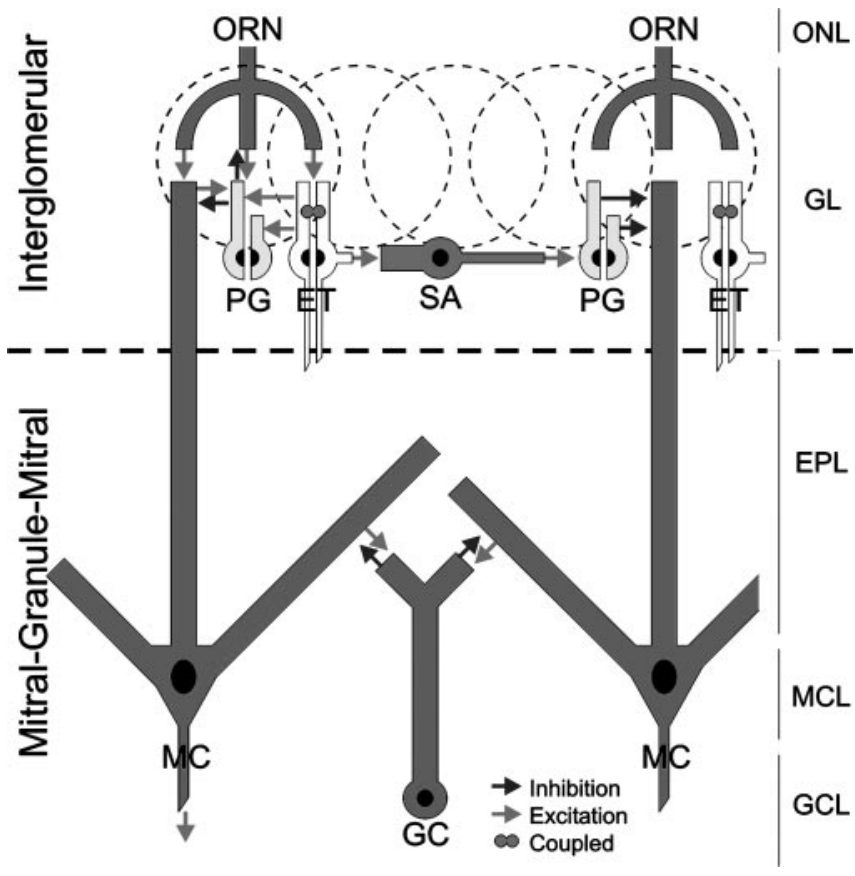

Figure 7. Schematic model of the intraglomerular circuitry. ET cells receive monosynaptic input from $\mathrm{ON}$ terminals. ET cells make monosynaptic excitatory glutamatergic synapses onto $P G$ and $S A$ cells of the same glomerulus. A subset of PG cells receives monosynaptic ON input. PG cell dendrites ramify in a restricted portion of a single glomerulus and thus may provide local intraglomerular inhibition via dendrodendritic interactions with ET or mitral cell (MC) dendrites. PG cells may also presynaptically inhibit ON terminals (Hsia et al., 1999; Wachowiak and Cohen, 1999; Aroniadou-Anderjaska et al., 2000; Ennis et al., 2001). SA cell axons project to multiple glomeruli and mediate center-surround inhibition (Aungst et al., 2003). Synchronously bursting ET cells are coupled and may coordinate the glomerular network.

nals. Calbindin-positive JG neurons extend their dendrites only into glomerular compartments devoid of ON terminals, suggesting that they do not receive direct sensory innervation (Toida et al., 1998, 2000). Thus, some PG cells lacking ON input in the present study may be calbindin positive. These PG cells might provide localized inhibition to mitral/tufted cell dendrites or other nearby JG cells. Dopaminergic and GABAergic PG cells presynaptically inhibit ON terminals (Hsia et al., 1999; Wachowiak and Cohen, 1999; Aroniadou-Anderjaska et al., 2000; Berkowicz and Trombley, 2000; Ennis et al., 2001). Because at least $20 \%$ of PG cells receive monosynaptic ON input, it is possible that they mediate presynaptic inhibition of the ON. In contrast to PG cells, SA cells extend dendrites and axons across multiple glomeruli and are involved in interglomerular functions, such as center-surround inhibition of neighboring glomeruli (Aungst et al., 2003) (Fig. 7).

\section{ET cells are a major excitatory relay in the glomerular circuit} All SA and PG cells respond to ON stimulation but SA and most PG cells lack monosynaptic ON input; however, ET cells do receive monosynaptic ON input and, as shown in the present experiments, provide monosynaptic excitatory glutamatergic input to SA/PG cells of the same glomerulus. Mitral/tufted cells may also relay $\mathrm{ON}$ input to PG/SA cells as they form asymmetrical excitatory dendrodendritic synapses with JG neurons (Pinching and Powell, 1971a,b; Toida et al., 1998, 2000; Kasowski et al., 1999). However, because (1) SA/PG cells receive spontaneous and ON-evoked bursts of EPSPs, (2) ET cells, but not mitral cells, spontaneously generate spike bursts in vitro (Heyward et al., 2001; Hayar et al., 2004), and (3) ET cells provide monosynaptic 
glutamatergic input to PG/SA cells, we conclude that ET cells are the predominant relay of ON input to PG/SA cells. This excitatory drive may be mediated by dendrodendritic synapses, because the morphological data (Hayar et al., 2004; this study) show that ET cell axons exit the glomerular layer with no discernable intraglomerular branching.

\section{ET cells coordinate glomerular activity}

A novel finding of the present study is the highly correlated spontaneous activity among ET and PG/SA neurons associated with the same glomerulus. This indicates that the mechanism(s) generating correlated activity is intraglomerular in nature. Synchrony was observed among ET and SA/PG cells that were monosynaptically coupled as expected, but also in pairs that were not monosynaptically coupled. This suggests that there is correlated activity among ET cells of the same glomerulus. Consistent with this, simultaneous recordings from pairs of ET cells showed that spontaneous bursting of ET cells of the same glomerulus is highly correlated. Moreover, the number of EPSCs per burst in PG cells (mean, 14.1 EPSCs per burst) far exceeds the mean number of spikes per burst in ET cells (mean, $5.4 \pm 0.3$ spikes per burst) (Hayar et al., 2004). This suggests that each PG cell receives convergent correlated input from multiple ET cells in the same glomerulus.

Correlated activity among ET and SA/PG cells is dependent on chemical synapses. When blockers of fast synapses are present, ET cells continue to burst, but spontaneous activity virtually ceases in PG and SA cells. In contrast, correlated activity among ET cells of the same glomerulus is not eliminated by fast synaptic blockers. This rules out release of glutamate from ON terminals, ET cells, or mitral/tufted cells (Aroniadou-Anderjaska et al., 1999; Isaacson, 1999; Carlson et al., 2000; Friedman and Strowbridge, 2000; Salin et al., 2001; Schoppa and Westbrook, 2001) as the primary mechanism underlying correlated activity among ET cells. It further indicates that $\mathrm{GABA}_{\mathrm{A}}$ receptor-mediated synapses are not required. What then does underlie the correlated activity among ET cells of the same glomerulus? We cannot exclude a role for other transmitters such as carnosine in ON fibers (Rochel and Margolis, 1982; Sassoe-Pognetto et al., 1993). Dopamine is expressed by some JG cells, and several neuropeptides are contained in JG cells as well as in tufted/mitral cells. The potential contribution of these transmitters as well as gap junctions (Schoppa and Westbrook, 2002) to correlated ET cell activity is not known.

\section{Glomerular synchrony and olfactory coding}

Temporal firing patterns, including neuronal synchronization and network oscillations, are thought to be important in sensory information processing (Alonso et al., 1996; Konig et al., 1996; Roy and Alloway, 2001), including odor coding (for review, see Friedrich, 2002). Odor-evoked activity in the mammalian olfactory bulb contains both fast and slow network oscillatory components (Laurent et al., 1996; Wehr and Laurent, 1996; Kauer, 1998; Kay and Laurent, 1999). Investigative sniffing and concomitant olfactory network oscillations occur in the slower theta frequency range (Adrian, 1950; Welker, 1964; Komisaruk, 1970; Macrides and Chorover, 1972). Patterned sensory input resulting from active "theta sniffing" is thought to establish rhythmical activity patterns in the olfactory bulb that enhance odor processing (Young and Wilson, 1999). ET cells are located at the first site of synaptic processing in the olfactory system, and they spontaneously generate rhythmic spike bursts that are highly correlated among ET cells of the same glomerulus (Hayar et al., 2004; this study). ET cell spike bursts are readily entrained by patterned sensory input at sniffing frequencies (Hayar et al., 2004). Thus, the "ensemble" of ET cells of each glomerulus might function as a network oscillator, the rhythm of which is entrained by patterned sensory input. The synchronous activity of the ET cell ensemble of a given glomerulus could provide synchronous excitatory burst onto mitral cells, the output neurons of the olfactory bulb. Indeed, mitral cells associated with the same glomerulus exhibit synchronous long-lasting depolarizations that are thought to be caused by a sustained recurrent excitatory synaptic activity of glomerular origin (Carlson et al., 2000; Schoppa and Westbrook, 2002). Because the temporal summation of EPSPs produced by coincident presynaptic bursts increases the likelihood of spike initiation in postsynaptic neurons (for review, see Lisman, 1997), synchronization of odor-evoked glomerular output (i.e., mitral cell spikes) by the ET cell network could ensure that glomerular output is faithfully transferred to higher-order olfactory structures.

\section{References}

Adrian ED (1950) The electrical activity of the olfactory bulb. Electroencephalogr Clin Neurophysiol 2:377-388.

Aertsen AM, Gerstein GL, Habib MK, Palm G (1989) Dynamics of neuronal firing correlation: modulation of "effective connectivity." J Neurophysiol 61:900-917.

Alonso JM, Usrey WM, Reid RC (1996) Precisely correlated firing in cells of the lateral geniculate nucleus. Nature 383:815-819.

Alvarez VA, Chow CC, Van Bockstaele EJ, Williams JT (2002) Frequencydependent synchrony in locus ceruleus: role of electrotonic coupling. Proc Natl Acad Sci USA 99:4032-4036.

Aroniadou-Anderjaska V, Ennis M, Shipley MT (1999) Dendrodendritic recurrent excitation in mitral cells of the rat olfactory bulb. J Neurophysiol 82:489-494.

Aroniadou-Anderjaska V, Zhou FM, Priest CA, Ennis M, Shipley MT (2000) Tonic and synaptically evoked presynaptic inhibition of sensory input to the rat olfactory bulb via GABA(B) heteroreceptors. J Neurophysiol 84:1194-1203.

Aungst JL, Heyward PM, Puche AC, Karnup SV, Hayar A, Szabo G, Shipley MT (2003) Center-surround inhibition among olfactory bulb glomeruli. Nature 426:623-629.

Belluscio L, Katz LC (2001) Symmetry, stereotypy, and topography of odorant representations in mouse olfactory bulbs. J Neurosci 21:2113-2122.

Berkowicz DA, Trombley PQ (2000) Dopaminergic modulation at the olfactory nerve synapse. Brain Res 855:90-99.

Carlson GC, Shipley MT, Keller A (2000) Long-lasting depolarizations in mitral cells of the rat olfactory bulb. J Neurosci 20:2011-2021.

Cinelli AR, Hamilton KA, Kauer JS (1995) Salamander olfactory bulb neuronal activity observed by video rate, voltage-sensitive dye imaging. III. Spatial and temporal properties of responses evoked by odorant stimulation. J Neurophysiol 73:2053-2071.

Doyle MW, Andresen MC (2001) Reliability of monosynaptic sensory transmission in brain stem neurons in vitro. J Neurophysiol 85:2213-2223.

Ennis M, Zhou FM, Ciombor KJ, Aroniadou-Anderjaska V, Hayar A, Borrelli E, Zimmer LA, Margolis F, Shipley MT (2001) Dopamine D2 receptormediated presynaptic inhibition of olfactory nerve terminals. J Neurophysiol 86:2986-2997.

Feldmeyer D, Egger V, Lubke J, Sakmann B (1999) Reliable synaptic connections between pairs of excitatory layer 4 neurones within a single "barrel" of developing rat somatosensory cortex. J Physiol (Lond) 521:169-190.

Friedman D, Strowbridge B (2000) Functional role of NMDA autoreceptors in olfactory mitral cells. J Neurophysiol 84:39-50.

Friedrich R (2002) Real time odor representations. Trends Neurosci 25:487-489.

Gerstein GL, Perkel DH (1972) Mutual temporal relationships among neuronal spike trains. Statistical techniques for display and analysis. Biophys J 12:453-473.

Hayar A, Karnup S, Shipley MT, Ennis M (2004) Olfactory bulb glomeruli: external tufted cells intrinsically burst at theta frequency and are entrained by patterned olfactory input. J Neurosci 24:1190-1199.

Heyward P, Ennis M, Keller A, Shipley MT (2001) Membrane bistability in olfactory bulb mitral cells. J Neurosci 21:5311-5320. 
Hsia AY, Vincent JD, Lledo PM (1999) Dopamine depresses synaptic inputs into the olfactory bulb. J Neurophysiol 82:1082-1085.

Isaacson JS (1999) Glutamate spillover mediates excitatory transmission in the rat olfactory bulb. Neuron 23:377-384.

Johnson BA, Leon M (2000a) Modular representations of odorants in the glomerular layer of the rat olfactory bulb and the effects of stimulus concentration. J Comp Neurol 422:496-509.

Johnson BA, Leon M (2000b) Odorant molecular length: one aspect of the olfactory code. J Comp Neurol 426:330-338.

Jourdan F, Duveau A, Astic L, Holley A (1980) Spatial distribution of $\left[{ }^{14} \mathrm{C}\right] 2$-deoxyglucose uptake in the olfactory bulbs of rats stimulated with two different odours. Brain Res 188:139-154.

Karnup S, Stelzer A (1999) Temporal overlap of excitatory and inhibitory afferent input in guinea-pig CA1 pyramidal cells. J Physiol (Lond) 516:485-504.

Kasowski HJ, Kim H, Greer CA (1999) Compartmental organization of the olfactory bulb glomerulus. J Comp Neurol 407:261-274.

Kauer JS (1998) Olfactory processing: a time and place for everything. Curr Biol 8:R282-R283.

Kay LM, Laurent G (1999) Odor- and context-dependent modulation of mitral cell activity in behaving rats. Nat Neurosci 2:1003-1009.

Komisaruk BR (1970) Synchrony between limbic system theta activity and rhythmical behavior in rats. J Comp Physiol Psychol 70:482-492.

Konig P, Engel AK, Singer W (1996) Integrator or coincidence detector? The role of the cortical neuron revisited. Trends Neurosci 19:130-137.

Kosaka K, Toida K, Margolis FL, Kosaka T (1997) Chemically defined neuron groups and their subpopulations in the glomerular layer of the rat main olfactory bulb-II. Prominent differences in the intraglomerular dendritic arborization and their relationship to olfactory nerve terminals. Neuroscience 76:775-786.

Kosaka K, Toida K, Aika Y, Kosaka T (1998) How simple is the organization of the olfactory glomerulus?: the heterogeneity of so-called periglomerular cells. Neurosci Res 30:101-110.

Laurent G, Wehr M, Davidowitz H (1996) Temporal representations of odors in an olfactory network. J Neurosci 16:3837-3847.

Lisman JE (1997) Bursts as a unit of neural information: making unreliable synapses reliable. Trends Neurosci 20:38-43.

Macrides F, Chorover SL (1972) Olfactory bulb units: activity correlated with inhalation cycles and odor quality. Science 175:84-87.

Mann-Metzer P, Yarom Y (1999) Electrotonic coupling interacts with intrinsic properties to generate synchronized activity in cerebellar networks of inhibitory interneurons. J Neurosci 19:3298-3306.
Pinching AJ, Powell TP (1971a) The neuron types of the glomerular layer of the olfactory bulb. J Cell Sci 9:305-345.

Pinching AJ, Powell TP (1971b) The neuropil of the glomeruli of the olfactory bulb. J Cell Sci 9:347-377.

Rochel S, Margolis FL (1982) Carnosine release from olfactory bulb synaptosomes is calcium-dependent and depolarization-stimulated. J Neurochem 38:1505-1514.

Roy SA, Alloway KD (2001) Coincidence detection or temporal integration? What the neurons in somatosensory cortex are doing. J Neurosci 21:2462-2473.

Salin PA, Lledo PM, Vincent JD, Charpak S (2001) Dendritic glutamate autoreceptors modulate signal processing in rat mitral cells. J Neurophysiol 85:1275-1282.

Sassoe-Pognetto M, Cantino D, Panzanelli P, Verdun di Cantogno L, Giustetto M, Margolis FL, De Biasi S, Fasolo A (1993) Presynaptic colocalization of carnosine and glutamate in olfactory neurones. NeuroReport 5:7-10.

Schoppa NE, Westbrook GL (2001) Glomerulus-specific synchronization of mitral cells in the olfactory bulb. Neuron 31:639-651.

Schoppa NE, Westbrook GL (2002) AMPA autoreceptors drive correlated spiking in olfactory bulb glomeruli. Nat Neurosci 5:1194-1202.

Toida K, Kosaka K, Heizmann CW, Kosaka T (1998) Chemically defined neuron groups and their subpopulations in the glomerular layer of the rat main olfactory bulb. III. Structural features of calbindin D28Kimmunoreactive neurons. J Comp Neurol 392:179-198.

Toida K, Kosaka K, Aika Y, Kosaka T (2000) Chemically defined neuron groups and their subpopulations in the glomerular layer of the rat main olfactory bulb-IV. Intraglomerular synapses of tyrosine hydroxylaseimmunoreactive neurons. Neuroscience 101:11-17.

Urban NN, Sakmann B (2002) Reciprocal intraglomerular excitation and intra- and interglomerular lateral inhibition between mouse olfactory bulb mitral cells. J Physiol (Lond) 542:355-367.

Wachowiak M, Cohen LB (1999) Presynaptic inhibition of primary olfactory afferents mediated by different mechanisms in lobster and turtle. J Neurosci 19:8808-8817.

Wehr M, Laurent G (1996) Odour encoding by temporal sequences of firing in oscillating neural assemblies. Nature 384:162-166.

Welker WI (1964) Analysis of sniffing of the albino rat. Behavior 22:223-244.

Xu F, Greer CA, Shepherd GM (2000) Odor maps in the olfactory bulb. J Comp Neurol 422:489-495.

Young TA, Wilson DA (1999) Frequency-dependent modulation of inhibition in the rat olfactory bulb. Neurosci Lett 276:65-67. 